\title{
Seismic isolation system of two hinged arch suspended-deck bridge: a case study on Kalikuto bridge - Indonesia
}

\author{
Tri Suryadi ${ }^{1 *}$, Arvila Delitriana ${ }^{2}, Z_{\text {denek Fukar }}^{3}$, and Rusri Tjendana ${ }^{4}$ \\ ${ }^{1}$ Seismic Division Manager, PT. Freyssinet Total Technology, Jakarta, Indonesia \\ ${ }^{2}$ Lead Structural Engineer, PT. Perentjana Djaja, Jakarta, Indonesia \\ ${ }^{3}$ Engineering Director, PT. Waagner Biro Indonesia, Jakarta, Indonesia \\ ${ }^{4}$ Senior Design Engineer, PT. Waagner Biro Indonesia, Jakarta, Indonesia
}

\begin{abstract}
Seismic isolation systems are widely used in buildings, bridges, and industrial structures all over the world. The system is known for the efficiency to reduce earthquake demand and thus provide better seismic performance of the structures. In particular to application in an arch suspended-deck bridge, seismic isolation system can be a solution for the seismic resisting system due to the incapability of the cable hangers to transfer horizontal forces from excitation mass on the hanging deck to the main compression arches. Kalikuto arch bridge that is built in 2018 has implemented both Lead Rubber Bearings and Seismic Rubber Expansion Joints as the part of its seismic resisting system. These two seismic isolation devices were designed and engineered accurately to fulfil the seismic design requirements of the Kalikuto bridge. Finally, several performance tests were conducted to evaluate the design compliance of the manufactured devices.
\end{abstract}

\section{Introduction}

Indonesia is an island country known for its seismic activity. This can be seen from seismic map released by the Public Works Department, where more than $70 \%$ of the regions are indicated as moderate to high seismic zones. In the development of the seismic codes and standards, the Indonesian seismic maps are usually updated with higher seismic coefficients for most of the regions due to additional indicated number of active faults. Particularly in Semarang-Batang region where Kalikuto bridge is located, the seismic coefficient is categorized as moderate seismicity with spectral coefficient at 1 second $\left(\mathrm{S}_{\mathrm{D} 1}\right)$ of $0.35 \mathrm{~g}$.

Kalikuto bridge is the part of Trans Java Toll Road which located in between two big cities in Central Java: Semarang and Batang. As the main landmark in this Semarang-Batang Toll Section, Kalikuto bridge is designed with a span configuration of 30-100-30 meters. Below are the specifications of the Kalikuto Bridge:

- Type of structure : Two Hinged Arch Bridge

- Overall Length $\quad: 160 \mathrm{~m}(30 \mathrm{~m}+100 \mathrm{~m}+30 \mathrm{~m})$

- Width $: 32.8 \mathrm{~m}$ (4 lanes traffic)

- Hangers : Freyssinet H-2000 Stay Cable

- Bearings : Lead Rubber Bearing

- Expansion Joint : SFX Seismic Expansion Joint

Due to a specific erection method, the arch has been designed as two hinge arch to support its own self weight and as fully restrained arch for the all remaining loads. The deck is suspended freely in lateral and longitudinal direction by strand hangers. The main load carrying structure consists of arch with welded steel box bracings.
The concrete deck is supported by grid system consisting of I-section welded cross girders and stringers. The concrete deck is designed to serve 4 lanes traffic that connects two big cities Semarang and Batang. This 4 lanes traffic requires the bridge to have an overall 32.8 meters width of concrete deck.

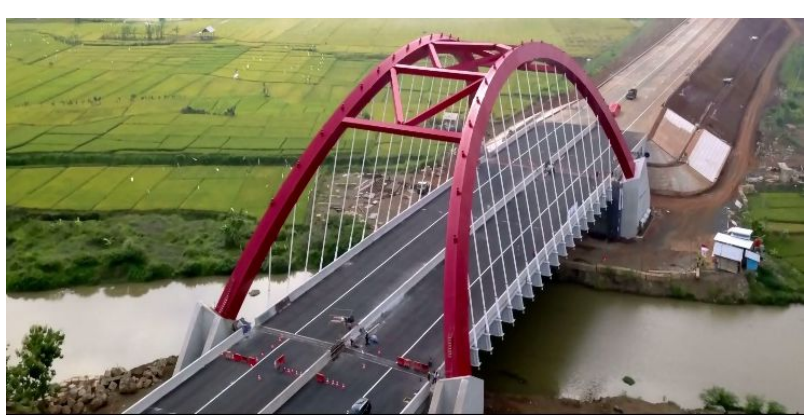

Fig. 1. Actual view of Kalikuto Bridge (Semarang - Batang)

With such an excessive weight on this wide concrete deck, it is obvious that any accelerations during earthquake could transform into huge horizontal earthquake force. The structural system must provide enough strength to overcome such potential issue.

\section{Arch Suspended-Deck System}

Arches behave like any two-dimensional beams with some supporting systems. Unlike the behaviour in simple beams structure, arches create a horizontal reaction on the supporting system that resist the tendency of the arch to open out. Considering only the arch element, arches can

\footnotetext{
* Corresponding author: tri.suryadi@,freyssinet.co.id
} 
be differentiated into 3 main types: fixed-fixed arch; two hinged arch; and three hinged arch:

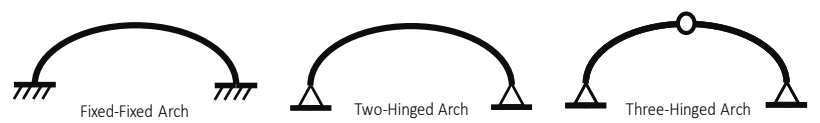

Fig. 2. Types of arch system

In a bridge system where the structure needs to connect two end locations, a deck structure must be provided either on the top of the arch element or even below the arch. If the bridge deck is placed completely above the arch, this system is named as "deck arch bridge". On the other hand, where the deck is placed below the arch, the system is simply named as "through arch bridge" because the deck passes through the arch. Kalikuto Bridge can be considered as a through arch bridge, where the deck is supported by the main arch system via suspension cable hangers.

Comparing to the typical through arch bridge where the suspension system from deck to the arch is connected by longitudinal tied beams, this Kalikuto Bridge was designed to have no tied beams at all. The suspension hangers are supporting the concrete deck directly through its cross beams / girders.

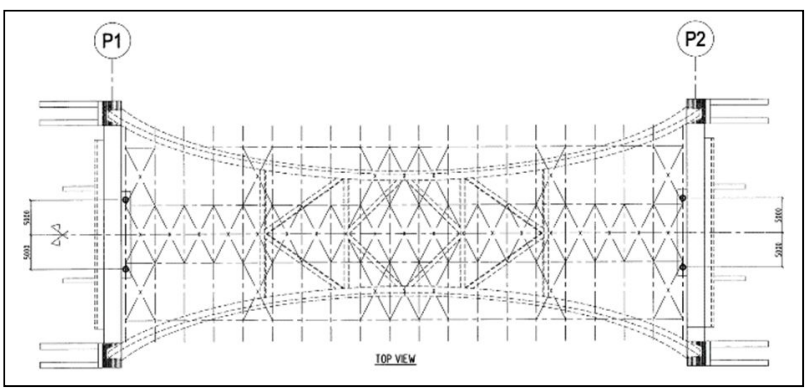

Fig. 3. Supporting system of Kalikuto Bridge

For the supporting (bearing) systems, there are only 4 bearings required, 2 at each side of the bridge (P1 and P2). These bearings are placed under the end cross girder of the deck system. The arch system is fixly anchored to a relatively rigid substructure. All the main gravitational loads from dead loads, superimposed loads, and traffic live loads are mostly transferred directly to the arch (and finally to the substructure) via cable hangers which are working only in axial tension direction. This cause a very small vertical reaction on the bearings comparing to the vertical reaction transmitted to the substructure at the bottom of the arch.

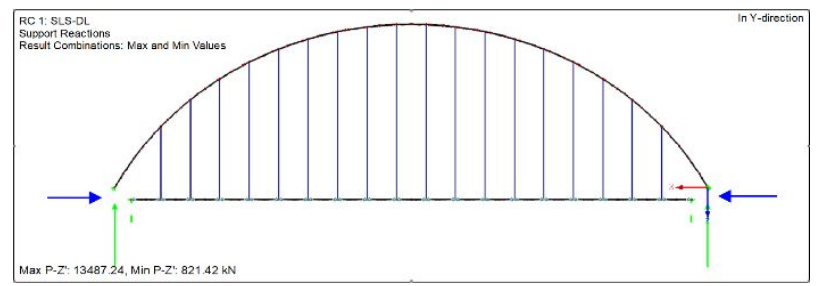

Fig. 4. Reaction on the bearing and bottom arch (dead loads)

Dead loads consist of steel self-weight, concrete deck and curb, corrugated steel deck and asphalt. All these loads are summed and give a total of about $57.250 \mathrm{kN}$ vertical force. This force will be transmitted to 4 bearings and 4 bottom arches. From figure 4, we can see the distribution of the force: $13487 \mathrm{kN}$ on the arch and 821 $\mathrm{kN}$ on the bearing. This bearing receives only about $6 \%$ of the total vertical load on the bridge.

\section{Conventional Bearing Issue}

Suspension cables has a crucial effect for both static and dynamic behaviors of the bridge. These hangers are tension members, and they are not capable to provide enough shear stiffness to resist any horizontal forces from earthquake, or even horizontal loads from service such as braking forces and wind loads on deck and vehicles. During the horizontal loading (from service and also earthquake), all these horizontal loads will be transmitted through the deck directly to the bearings. As the result, there will be an excessive horizontal reaction accumulated on the bearings or supports.

In a normal circumstance, where the bridge is only equipped with conventional bearings (two fixed bearings on one side and two roll bearings on the other side), the resulted horizonal reaction can be even worse. Because now the horizontal load is not distributed to 4 bearings, but to only 2 bearings. Taking above total dead loads $(57.250 \mathrm{kN})$ as the total excitation mass, these two bearings will receive about $10.000 \mathrm{kN}$ horizontal force (assuming that the dominant conventional mode is $1.0 \mathrm{sec}$ [100\% mass participation ratio] and the value of acceleration spectral at $1-\mathrm{sec}$ is $0.35 \mathrm{~g}[0.35 \times 57.250] / 2$ $\approx 10.000 \mathrm{kN})$.

With that simplified assumption, we will end up having a fixed bearing with $10.000 \mathrm{kN}$ horizontal reaction and only $821 \mathrm{kN}$ vertical reaction. The ratio between horizontal and vertical reaction is even more than 12 . It is of course very difficult and uneconomical to design such bearing as conventional pot bearing or spherical bearing. There would also not enough space for such large bearings in the substructure.

\section{Seismic Isolation System of Kalikuto}

An alternative solution needs to be addressed to overcome the issue on the original conventional bearings. Lead Rubber Bearings are then chosen for this reason. With the $\mathrm{LRB}$, it is expected to distribute all the horizontal force to all the 4 bearings. And furthermore, the isolation and dissipation mechanisms feature from LRB can also reduce the earthquake demand on the bridge and substructure.

The LRB is designed to have enough rigidity during service and static condition and at the same time also to have enough flexibility during seismic motion in order to reduce and isolate the earthquake force. A trial and error process in obtaining correct parameter of LRB is mandatory because another objective in this project is also to limit the deck displacement during seismic event, to make sure the changes in the angle of all hangers are kept below the allowable limits. In this case study, the maximum seismic design displacement of the deck is kept maximum at $205 \mathrm{~mm}$. 
To accommodate such displacement during seismic event, a special expansion joint shall be used. Particularly for this project, a seismic mat joint called Seismic SFX Joint is provided for such purpose. SFX Joint is designed to move perfectly without damage in both longitudinal and transversal directions. The joints are placed at the end of the bridge exactly at axis of P1 and P2 (fig. 3).

During the construction of the project, both LRB and SFX were also tested according to the designed displacement to show that the manufactured products are complying to the design.
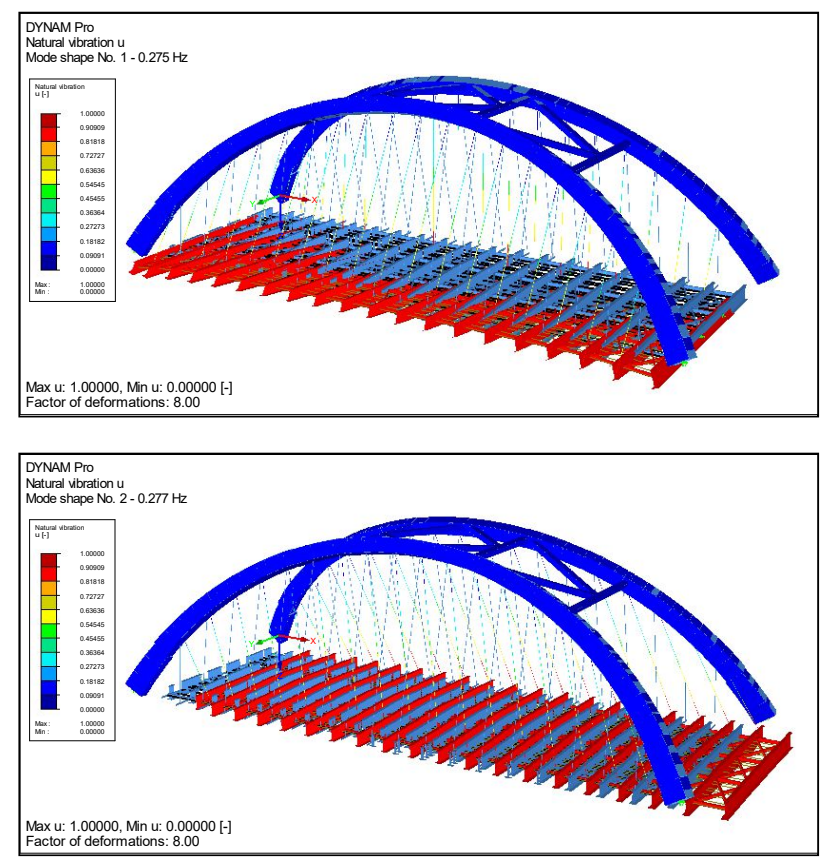

Fig. 5. Mode shapes of the structure with LRB (Transversal and Longitudinal Mode)

Following the concept of seismic isolation, where the isolator devices shall have enough flexibility to un-couple the dynamic behavior of the superstructure and substructure, LRB with diameter of $750 \mathrm{~mm}$ is designed for this bridge. During the seismic displacement, this LRB will have an effective linearized stiffness of $4.16 \mathrm{kN} / \mathrm{mm}$ in both transversal and longitudinal direction. In the vertical direction, the bearing can provide a linear stiffness of about $1400 \mathrm{kN} / \mathrm{mm}$. This vertical stiffness was then tested to reconfirm this assumption. Below are the mode shapes of the structure in both longitudinal and transversal directions. Each mode has a mass participation ratio of about $84 \%$. The rest of the masses were not excited in this dominant $1^{\text {st }}$ mode because they are masses from the arches and top bracings which are not transmitted to the LRB.

Both isolators and seismic joints were tested in Freyssinet's Laboratory (ISOLAB) in Milano - Italia. Such performance test is very important to show the compliance of the manufactured devices. Both devices were statically and dynamically tested for this purpose. Client's representatives were also invited to witness the test to keep the objectivity of the procedure.

The test results showed that the LRB is complying with design requirements. There was not found any damage and failure during visual inspection of the two tests (compression and dynamic horizontal test). From the compression test result, the obtained vertical stiffness matches the design assumption quite accurately. From the horizontal cyclic test, the obtained effective damping and stiffness at seismic displacement were also in the range of acceptance limit (+/- 20\% from the design values). Note that the acceptance criteria in this project is based on requirement in EN 15129 Anti-Seismic Devices.

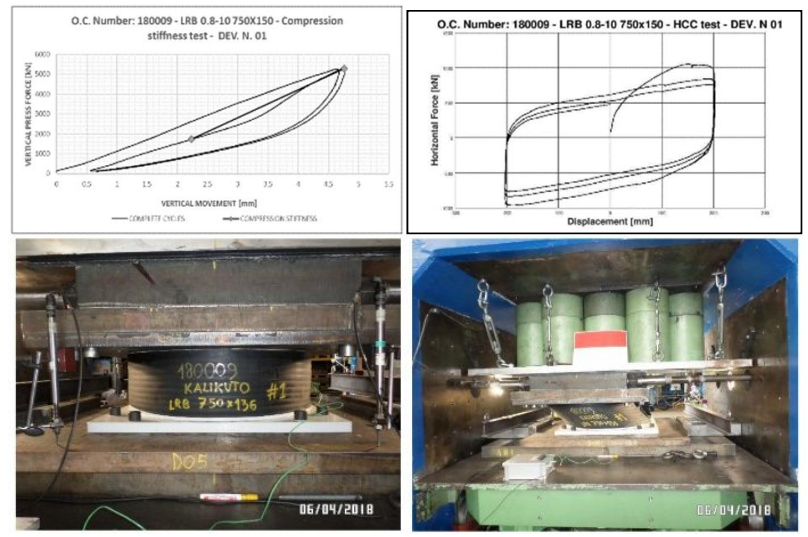

Fig. 6. Documentations during LRB Test (Compression stiffness test and horizontal characteristic)

Below are the tabulations of the testing results for both compression and horizontal cyclic tests.

Table 1. LRB performance test result

\begin{tabular}{|c|c|c|c|c|c|c|c|}
\hline \multicolumn{2}{|c|}{ Device type } & $\begin{array}{c}\text { Device } \\
\#\end{array}$ & \begin{tabular}{|c|}
$\begin{array}{c}\text { Vertical } \\
\text { load }\end{array}$ \\
{$[\mathrm{kN}]$} \\
\end{tabular} & \begin{tabular}{|c|} 
Displ. \\
{$[\mathrm{mm}]$} \\
\end{tabular} & $\begin{array}{c}\begin{array}{c}\text { Vertical } \\
\text { stiffness, } \mathbf{K}_{v}\end{array} \\
{[\mathbf{k N} / \mathbf{m m}]}\end{array}$ & \multicolumn{2}{|c|}{$\begin{array}{c}\text { Visual } \\
\text { inspection } \\
\text { results }\end{array}$} \\
\hline \multicolumn{2}{|c|}{ LRB 0.8-10 750x150 } & 1 & 5270 & & 1408 & Noret & \\
\hline \multirow[t]{3}{*}{ Device type } & \multirow[t]{2}{*}{$\begin{array}{c}\text { Device } \\
\#\end{array}$} & \multicolumn{2}{|c|}{$\begin{array}{c}\text { Damping } \\
\text { factor, (at d dba) } \\
\xi \mathrm{b}\end{array}$} & $\begin{array}{c}\text { Expected } \\
\text { valuc }{ }^{*}, \xi \boldsymbol{g} \mathbf{b}\end{array}$ & \multicolumn{2}{|c|}{$\begin{array}{c}\text { Horizontal } \\
\text { stiffness (at d } \text { bad } \text { ), } \\
\mathbf{K b}\end{array}$} & $\begin{array}{c}\text { Expected } \\
\text { value }, \mathbf{K b}\end{array}$ \\
\hline & & \multicolumn{2}{|c|}{$[\%]$} & {$[\%]$} & \multicolumn{2}{|c|}{$[\mathrm{Kn} / \mathbf{m m}]$} & {$[\mathrm{kN} / \mathrm{mm}]$} \\
\hline & 1 & \multicolumn{2}{|c|}{41.34} & $38.6 \pm 7.72$ & \multicolumn{2}{|c|}{3.76} & $4.16 \pm 0.83$ \\
\hline
\end{tabular}

Another testing procedure was also performed on the expansion joint. This particular system has negligible contribution for the seismic isolation, but it is a very crucial part of the bridge system at the same time, because it should have capacity to accommodate large movements on the concrete deck during earthquake so that the concrete deck will not collide to the adjacent structure. This expansion joint shall be also designed to withstand vertical load from vehicles and design truck while having service movements from braking loads, temperature, creep, and shrinkage.

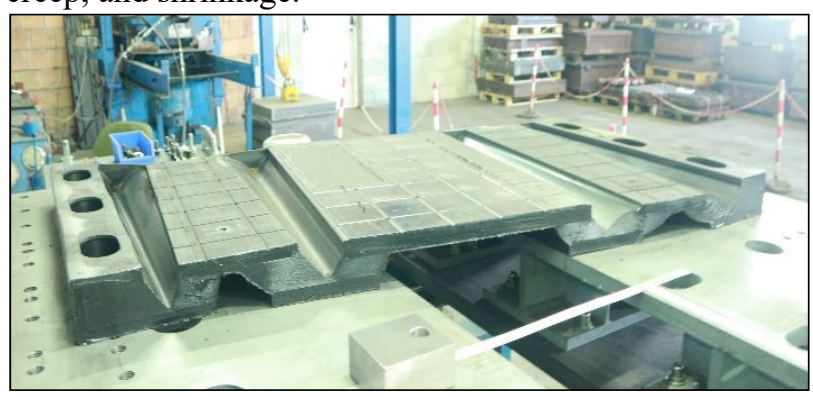

Fig. 7. Documentation from Seismic SFX Joint Test (Simultaneous movement of Long - Trans) 
The Seismic SFX Joint was tested to the design movements in longitudinal, transversal, and orthogonal directions. At the end of the test procedure, this panel joint was even re-tested to an extended movement of about 230 $\mathrm{mm}$ to fulfill the additional request from the client's representative. There was no evidence of rubber cracks, steel plate debonding, or anchor failure on the expansion joint system. The joint was in complete same shape without permanent deformations before and after the test was performed.

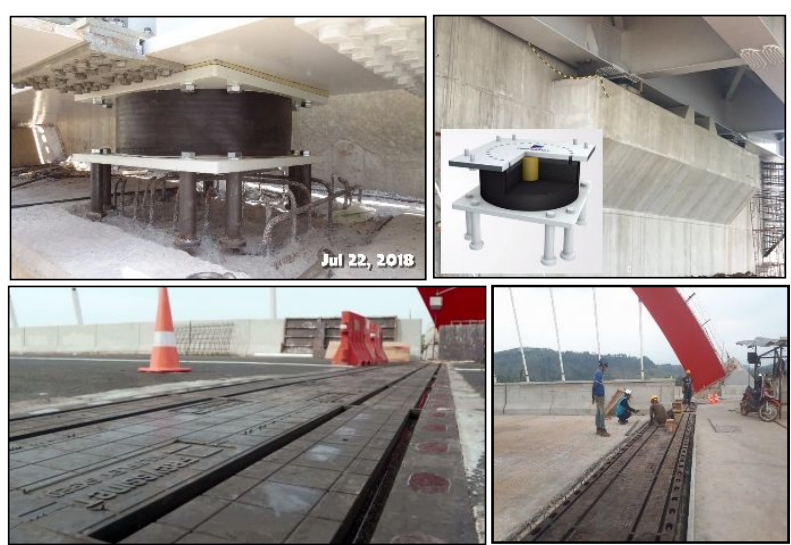

Fig. 8. Documentations of LRB and SFX Joint on site

The bridge construction was finished on mid of 2018 . All the Lead Rubber Bearings and Seismic SFX Joints were installed and supervised based on the installation procedures provided by Freyssinet. Later after the construction, the bridge was then statically and dynamically tested before it is officially inaugurated by the President on December 2018.

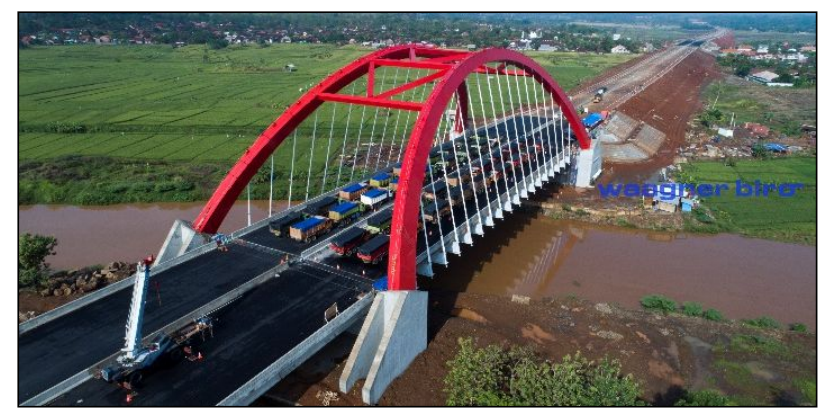

Fig. 9. Kalikuto Bridge during Loading Test (Picture by: $P T$. Waagner Biro Indonesia)

\section{Conclusion}

Kalikuto bridge is a good example of effective application of seismic isolation system in an arch bridge structure. The use of Lead Rubber Bearing in this bridge has solved a big issue of conventional bearings application on a suspended-deck arch bridge. Due to the incapability of the hangers to transmit shear forces to the arch (and later to the foundation), all horizontal forces from the deck will be accumulated to the bearings. Replacing the conventional bearing with LRB, this horizontal force accumulation is significantly reduced. LRB provides both isolation and energy dissipation mechanisms to finally reduce horizontal EQ load on the bearing.

With the application of LRB in Kalikuto bridge, the vibration period of the structure at seismic condition will be quite high. This is directly effecting the resulted seismic displacement of the structural system, which in this case will be essentially big. In order to accommodate such big movements, a corresponding seismic expansion joint is provided. A special seismic mat rubber joint called SFX Joint is then chosen to provide the solution. This seismic joint will be freely moving in both longitudinal and transversal directions during seismic events. Proper clearance or gap is also provided for this expansion joint, to avoid any collisions on the deck during seismic.

\section{References}

1. European Committee for Standardization (CEN), "European Standard EN 15129: 2009 - Anti Seismic Devices", (2009).

2. Buckle, I., Al-Ani, M., and Monzon, E., "Seismic Isolation Design Examples of Highway Bridges", NCHRP 20-7 / Task 262 (M2), (2011).

3. AASHTO (American Association of State Highway and Transportation Officials) "Guide Specification for Seismic Isolation Design" 4th Edition, AASHTO, Washington, D.C, (2014).

4. Suryadi, T., Sihaloho, D., Fukar, Z., The 3rd international Conference on Earthquake Engineering and Disaster Mitigation, (2016).

5. Sartori, M., Cynober, C., Correa, C., Vallejo, H., Meza, A., Suryadi, T., 16th European Conference on Earthquake Engineering, (2018).

6. Cynober, C., Suryadi, T., Sartori, M., 40 ${ }^{\text {th }}$ IABSE Symposium New Trends for Innovations in The Construction, The Preservation, The Exploitation and The Upgrading of Structures, (2018).

7. Suryadi, T., INTAKINDO International Conference on Construction Technology \& Innovation, (2019).

8. Barone, S., Sartori, M., Suryadi, T., Zivanovic, I., 16th World Conference on Seismic Isolation, Energy Dissipation, and Active Vibration Control of Structures, (2019).

9. Suryadi, T., Sihite, T., 16th World Conference on Seismic Isolation, Energy Dissipation, and Active Vibration Control of Structures, (2019). 